\title{
PMCA4 gene expression is regulated by the androgen receptor in the mouse testis during spermatogenesis
}

\author{
RUI SUN ${ }^{1}$, HUI LIANG ${ }^{1}$, HUAN GUO $^{2}$, ZHU WANG ${ }^{1}$ and QIONG DENG $^{1,3}$ \\ ${ }^{1}$ Department of Urology, The People's Hospital of Longhua, The Affiliated Hospital of Southern Medical University, \\ Shenzhen, Guangdong 518109; ${ }^{2}$ Department of Urology, Shenzhen University General Hospital and Shenzhen University \\ Clinical Medical Academy Center, Shenzhen University, Shenzhen, Guangdong 518052; ${ }^{3}$ Central Laboratory, \\ The People's Hospital of Longhua, The Affiliated Hospital of Southern Medical University, \\ Shenzhen, Guangdong 518109, P.R. China
}

Received July 31, 2020; Accepted November 30, 2020

DOI: $10.3892 / \mathrm{mmr} .2020 .11791$

\begin{abstract}
The present study aimed to investigate the expression of ATPase $\mathrm{Ca}^{++}$transporting plasma membrane 4 (PMCA4) in mouse testis and to determine its role in spermatogenesis. Reverse transcription-quantitative PCR, western blotting and immunofluorescence were performed to evaluate the expression levels of PMCA4 in mouse testes at various weeks postnatal in wild type mice, and in testes from Sertoli cell-specific androgen receptor knockout and androgen receptor knockout (ARKO) mice. Luciferase assay, androgen receptor (AR) overexpression and AR antagonist experiments were used to confirm that AR regulated the expression of PMCA4. The results demonstrated that PMCA4 was highly expressed in mouse testes at 3-8 weeks postnatal. PMCA4 expression levels in ARKO mouse testes were decreased compared with wild type. In addition, activation of AR by testosterone administration resulted in an increase in the activity of the PMCA4 promoter. Cells transfected with an AR-overexpressing plasmid exhibited increased expression levels of the PMCA4 protein. Finally, the increase in PMCA4 protein levels induced by testosterone was prevented by pre-treatment with the AR antagonist flutamide. The present results confirmed that PMCA4 was upregulated during mouse testis development and that PMCA4 mRNA and protein expression levels were regulated by androgens and AR. The present findings suggest that PMCA4 may be involved in the regulation of spermatogenesis.
\end{abstract}

Correspondence to: Dr Qiong Deng, Department of Urology, The People's Hospital of Longhua, The Affiliated Hospital of Southern Medical University, 38 Jinglongjianshe Road, Longhua, Shenzhen, Guangdong 518109, P.R. China

E-mail: dengqiong1987@smu.edu.cn

Key words: ATPase $\mathrm{Ca}^{++}$transporting plasma membrane 4, spermatogenesis, testis, androgen receptor

\section{Introduction}

Androgens and androgen receptors (ARs) have a crucial role in maintaining spermatogenesis (1). Increasing evidence has demonstrated that low testosterone levels and mutations in the AR gene could result in spermatogenesis failure and male infertility (2-4). A previous study using a Sertoli cell-specific AR knockout (SCARKO) mouse model revealed spermatogenesis arrest at the diplotene stage (5), indicating that the function of androgens in Sertoli cells is critical for spermatogenesis.

Free testosterone binds to cytoplasmic AR in Sertoli cells, inducing a conformational change in $\mathrm{AR}$ and the nuclear translocation of the testosterone/AR complex. Subsequently, the complex binds to the androgen response element (ARE) in the chromatin, to induce target gene transcriptional activation or repression (1). At present, reproductive homeobox 5 is the only target gene that has been identified (6). Therefore, additional AR target genes, that may be physiologically relevant to spermatogenesis, need to be identified.

Our previous study (7) showed that ATPase $\mathrm{Ca}^{++}$transporting plasma membrane 4 (ATP2B4, also known as PMCA4) was one of the 2,276 downregulated genes in AR knockout (ARKO) mice compared with WT mice. PMCA4 belongs to the family of P-type primary ion transport ATPases, which have key roles in intracellular $\mathrm{Ca}^{2+}$ homeostasis (8). Schuh et al (9) demonstrated that PMCA4 is required for sperm motility and male fertility in mice, while Patel et al (10) showed that PMCA4 is critical for murine sperm maturation. Olli et al (11) found that deletion of PMCA4 gene resulted in decreased sperm motility and infertility and suggested the potential involvement of PMCA4 mutations in human asthenospermia. However, the underlying mechanism responsible for the decreased sperm motility resulting from the absence or knockdown of PMCA4 has not been fully elucidated (11). The present study aimed to explore the expression pattern and function of PMCA4 during mouse spermatogenesis.

\section{Materials and methods}

Animals. A total of 30 C57BL/6 male mice were purchased from Guangdong Experimental Animal Center (Foshan, 
China). SCARKO $(n=3)$ and ARKO $(n=3)$ mice were provided by Dr Yaoting Gui, at the Peking University Shenzhen Hospital (Shenzhen, China). Experimental protocols involving animals were reviewed and approved by the ethics committee of The People's Hospital of Longhua (Shenzhen, China; approval no. LHRY-1907014). ARKO mouse testes were collected from 8-9-week-old mice. WT postnatal testes were collected from C57BL/6 mice aged 1-8 weeks (3 mice in each group). Samples from other organs mentioned in the present study were from C57BL/6 adult mice (age, 8-9 weeks; $n=6$ ). Mice were maintained for at least 5 days under standard conditions with water and chow ad libitum and a $16-\mathrm{h} \mathrm{light} / 8$-h dark cycle at $22-25^{\circ} \mathrm{C}$ and $50-60 \%$ relative humidity. Euthanasia was performed by cervical dislocation after $\mathrm{CO}_{2}$ sedation.

Reverse transcription-quantitative PCR (RT-qPCR). Total RNA was extracted from mouse testes using TRIzol (Thermo Fisher Scientific, Inc.) and cDNA synthesis was performed using the PrimeScript RT Master Mix kit (Takara Bio, Inc.) according to the manufacturer's protocol. RT-qPCR reactions were performed with the SYBR ${ }^{\circledR}$ Premix EX TaqTMII PCR kit (Takara Bio, Inc.), with primers specific for mouse PMCA4 (forward, 5'-CTGAGGGAATGGACGAGAT-3' and reverse, 5'-CAACTGCTGCGGAATAGGA-3'; product size, 204 bp), with GAPDH (forward, 5'-AGTGGCAAAGTGGAGATT-3'; and reverse, 5'-GTGGAGTCATACTCCAACA-3'; product size, $116 \mathrm{bp}$ ) used as the endogenous control. The annealing temperature was $60^{\circ} \mathrm{C}$, with 40 cycles. Data were calculated using $2^{-\Delta \Delta \mathrm{Cq}}$ method (12).

Western blot analysis. Protein samples were extracted from tissue and cells using RIPA lysis buffer (Beyotime Institute of Biotechnology), then $20 \mu \mathrm{g}$ protein samples (determined by bicinchoninic acid) were loaded and run on $10 \%$ SDS-PAGE, and transferred onto a polyvinylidene fluoride (PVDF) membrane. The membranes were blocked with $10 \%(\mathrm{w} / \mathrm{v})$ non-fat milk in TBS buffer (Dalian Meilun Biology Technology Co., Ltd.) with $0.05 \%$ Tween-20 (Sigma-Aldrich; Merck $\mathrm{KGaA}$ ) at room temperature for $1 \mathrm{~h}$. After incubation overnight at $4^{\circ} \mathrm{C}$ with primary antibodies targeting PMCA4 (140 kDa, Abcam; cat. no. ab2783; 1:1,000 dilution), GAPDH (37 kDa, Cell Signaling Technology, Inc.; cat. no. 5174; 1:1,000 dilution), or AR (110 kDa, Santa Cruz Biotechnology, Inc., cat. no. sc-816; 1:1,000). The membranes were treated with horseradish peroxidase-labeled secondary antibody (anti-rabbit and anti-mouse IgG; both 1:1000; cat nos. 7074 and 7076, respectively; both Cell Signaling Technology, Inc.) for $1 \mathrm{~h}$ at room temperature. Positive bands were detected using an enhanced chemiluminescence kit (Thermo Fisher Scientific, Inc.). The densitometry was determined by ImageJ 1.48 software (imagej.net/).

Sperm collection. Mouse epididymides for sperm preparation were collected from C57BL/6 mice as described previously (13). Briefly, cauda epididymis was dissected and placed in Quinn's Advantage Fertilization (HTF) Medium (pH 7.4; SAGE $^{\circledR}$ Media; cat. no. ART-1020; Cooper Surgical, Inc.) at $37^{\circ} \mathrm{C}$ for $10 \mathrm{~min}$ following shearing, to allow the sperm to be dispersed. After a wash with fresh medium, the sperm was centrifuged at $800 \mathrm{xg}$ for $10 \mathrm{~min}$ at room temperature, and then resuspended in fresh Quinn's medium $\left(1 \times 10^{7}\right.$ cells $\left./ \mathrm{ml}\right)$ for the next step of experiments.

Immunofluorescence. Mouse testes were dissected, fixed with $4 \%$ paraformaldehyde for $24 \mathrm{~h}$ at $4{ }^{\circ} \mathrm{C}$, then embedded in paraffin. The paraffin-embedded testicular tissue was cut in $2-\mu \mathrm{m}$ sections. After dewaxing and rehydrating, the slides were subjected to antigen retrieval, by immersing in $10 \mathrm{mM}$ sodium citrate (pH 6.0) and microwaving at $1,000 \mathrm{~W}$ for $30 \mathrm{~min}$. The sections were blocked in $10 \%$ bovine serum albumin at $37^{\circ} \mathrm{C}$ for $30 \mathrm{~min}$, followed by cooling to room temperature (RT). An anti-PMCA4 antibody (1:100; cat. no. ab2783; Abcam) was added on to the slides and kept at $4{ }^{\circ} \mathrm{C}$ overnight. The following day, after three washes with PBS, the sections were incubated with an anti-mouse Alexa Fluor 594 antibody (1:500; cat. no. A-11005; Thermo Fisher Scientific, Inc.) for $1 \mathrm{~h}$ at RT. The sections were counterstained with Hoechst 33342 (1:2,000; Invitrogen; Thermo Fisher Scientific, Inc.) for $5 \mathrm{~min}$ at RT. Following two additional washes, the sections were mounted with SlowFade (Invitrogen; Thermo Fisher Scientific, Inc.) and observed using a fluorescent microscope (magnification, x200; Zeiss $\mathrm{GmbH}$ ).

Cell transfection. Murine Sertoli cell line TM4 was purchased from the American Type Culture Collection. Cells were cultured in DMEM (Gibco; Thermo Fisher Scientific, Inc.) containing $10 \%$ fetal bovine serum $(\mathrm{v} / \mathrm{v})$ and $100 \mu \mathrm{g} / \mathrm{ml}$ each penicillin and streptomycin at $37^{\circ} \mathrm{C}$ with atmospheric conditions of $95 \%$ air and $5 \% \mathrm{CO}_{2}$. Plasmids pcDNA3.1-AR and pcDNA3.1 were constructed by IGE Biotechnology Ltd. Cells were plated in $10-\mathrm{cm}$ culture dishes; upon reaching $50 \%$ confluence, cells were transfected $\left(37^{\circ} \mathrm{C} ; 24-48 \mathrm{~h}\right)$ with $2.5 \mu \mathrm{g}$ plasmid using Lipofectamine $^{\circledR} 3000$ (Thermo Fisher Scientific, Inc.). Cells were harvested $24-48 \mathrm{~h}$ after transfection.

Dual-luciferase assay. At $24 \mathrm{~h}$ post-transfection, TM4 cells were cultured in serum-free medium [0.1\% BSA in DMEM (cat. no. C11995500BT; Gibco; Thermo Fisher Scientific, Inc.)] for $6 \mathrm{~h}$ before addition of $10 \mathrm{nM}$ testosterone (Dalian Meilun Biology Technology Co., Ltd.) or ethanol. Following $6 \mathrm{~h}$ incubation at $37^{\circ} \mathrm{C}$ and removal of the medium, cells were lysed by addition of $100 \mu \mathrm{l}$ passive lysis buffer (Promega Corporation). Luciferase activity was measured following the manufacturer's instructions (cat. no. E1910; Promega Corporation). The activity of luciferase reporter was normalized to that of Renilla luciferase.

Statistical analysis. All experiments in the present study were repeated at least three times. Statistical analysis was performed using Sigmaplot 16.0 (Systat Software, Inc.). Data were expressed as the mean \pm standard error of mean. Statistical significance was evaluated by one -way ANOVA followed by Fisher's protected least-significant difference post hoc test, unless otherwise specified. $\mathrm{P}<0.05$ was considered to indicate a statistically significant difference.

\section{Results}

Expression levels of PMCA4 during mouse testes development. First, the protein expression levels of PMCA4 were 


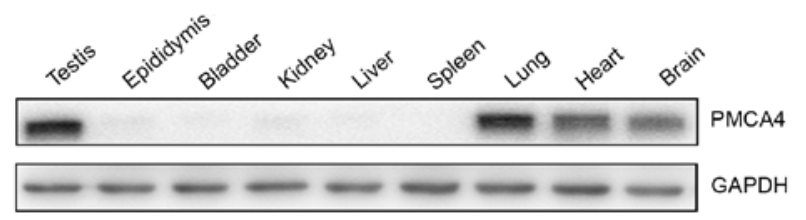

Figure 1. Expression of PMCA4 in different mouse tissues. Western blot analysis of PMCA4 protein expression in various tissues form adult C57BL/6 mice. GAPDH was used as in internal control. PMCA4, ATPase $\mathrm{Ca}^{++}$transporting plasma membrane 4 .
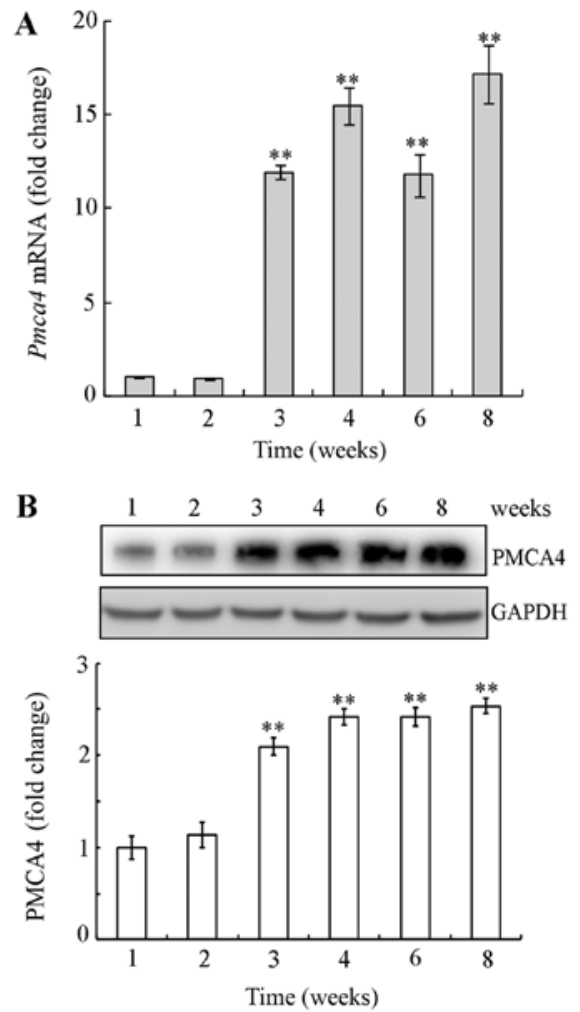

Figure 2. Temporal expression of PMCA4 during mouse testis postnatal development. (A) mRNA expression levels were evaluated at 1, 2, 3, 4, 6 and 8 weeks postnatal. mRNA levels were normalized to GAPDH and plotted relative to those of the 1-week-old mice. (B) Protein expression levels were detected by western blotting, with GAPDH used an internal control. Data were analyzed by one-way ANOVA followed by post hoc Bonferroni's test and are presented as mean \pm standard error of the mean $(n=4){ }^{* *} \mathrm{P}<0.01$ vs. 1 week. PMCA4, ATPase $\mathrm{Ca}^{++}$transporting plasma membrane 4; w, week.

examined in various tissues from adult mice. Western blotting results revealed that the PMCA4 protein was expressed in the testes, as well as in the lung, heart and brain (Fig. 1). No protein expression of PMCA4 was observed in epididymis, bladder, liver, kidney and spleen tissue (Fig. 1).

Next, the mRNA and protein expression levels of PMCA4 were examined by RT-qPCR and western blotting, respectively, in mouse testicular tissues during postnatal development. PMCA4 expression levels were significantly increased at week 3-8 postnatal compared with week 1, both at the mRNA and the protein level (Fig. 2). These findings suggest that PMCA4 was upregulated during mouse testes postnatal development.

PMCA4 expression is decreased in the testes of AR-knockout mice. To confirm the results from our previous gene expres-
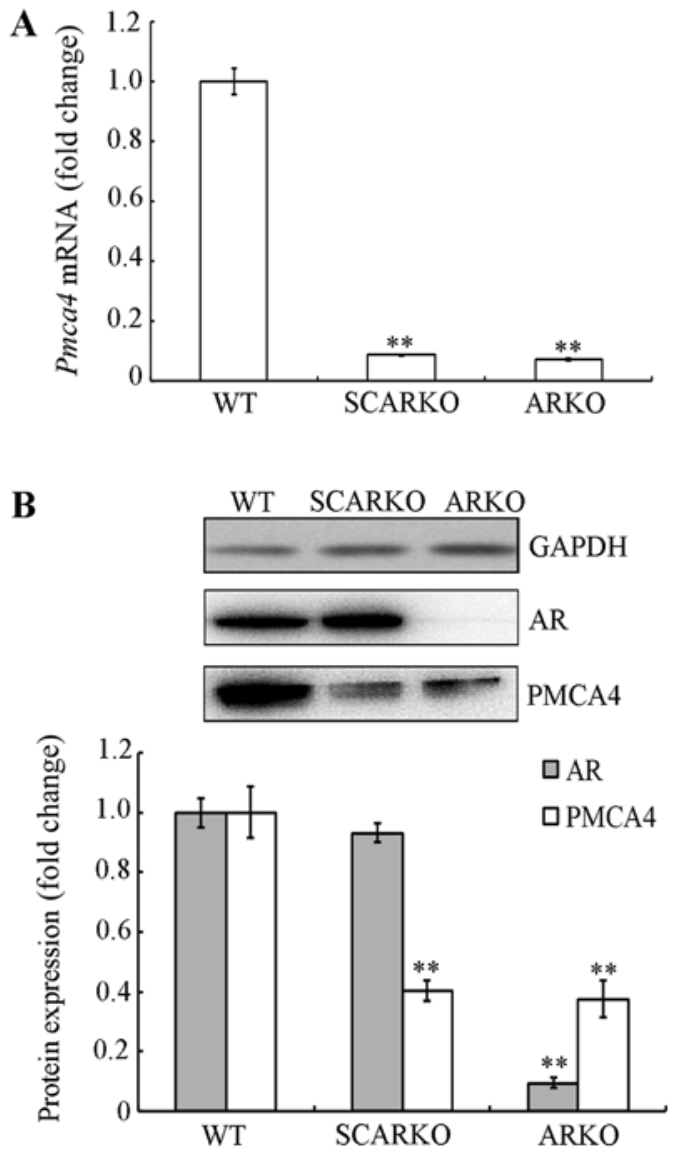

Figure 3. PMCA4 expression is decreased in testes from ARKO mice. (A) mRNA and (B) protein expression levels of PMCA4 were evaluated in WT, SCARKO and ARKO mouse testes. Data are presented as the mean \pm standard error of the mean relative to the WT group $(n=4)$ ${ }^{* *} \mathrm{P}<0.01$ vs. WT. PMCA4, ATPase $\mathrm{Ca}^{++}$transporting plasma membrane 4; AR, androgen receptor; WT, wild type; SCARKO, Sertoli cell-specific AR knockout; ARKO, AR knockout.

sion analysis (8), PMCA4 mRNA and protein expression levels were examined in the testes of SCARKO, ARKO and WT mice. Compared with WT mice, PMCA4 mRNA levels were decreased in testicular tissues from SCARKO $(0.087 \pm 0.002$; $\mathrm{P}<0.001)$ and ARKO $(0.075 \pm 0.004 ; \mathrm{P}<0.001)$ mice (Fig. $3 \mathrm{~A})$. Similar results were obtained for the protein expression levels, as shown in Fig. 3B. These findings indicated that PMCA4 expression was decreased in AR knockout mice, thus, it was hypothesized that PMCA4 may be regulated by AR in mouse testes.

PMCA4 expression during spermatogenesis. To further explore the potential role of PMCA4 in spermatogenesis, the subcellular localization of PMCA4 during testes development was investigated by immunofluorescence staining. As presented in Fig. 4, PMCA4 immunostaining was absent before 3 weeks postnatal. In addition, the staining pattern in the microscopy images revealed that PMCA4 expression was located in the elongated spermatids (Fig. 4).

Next, immunofluorescence staining for PMCA4 was performed in testicular tissues from WT and ARKO mice. In the testis from WT mice, high intensity fluorescence (red) was observed in the lumen of the testicular tubule and was co-localized with the mature sperm (Fig. 5). Consistent with 


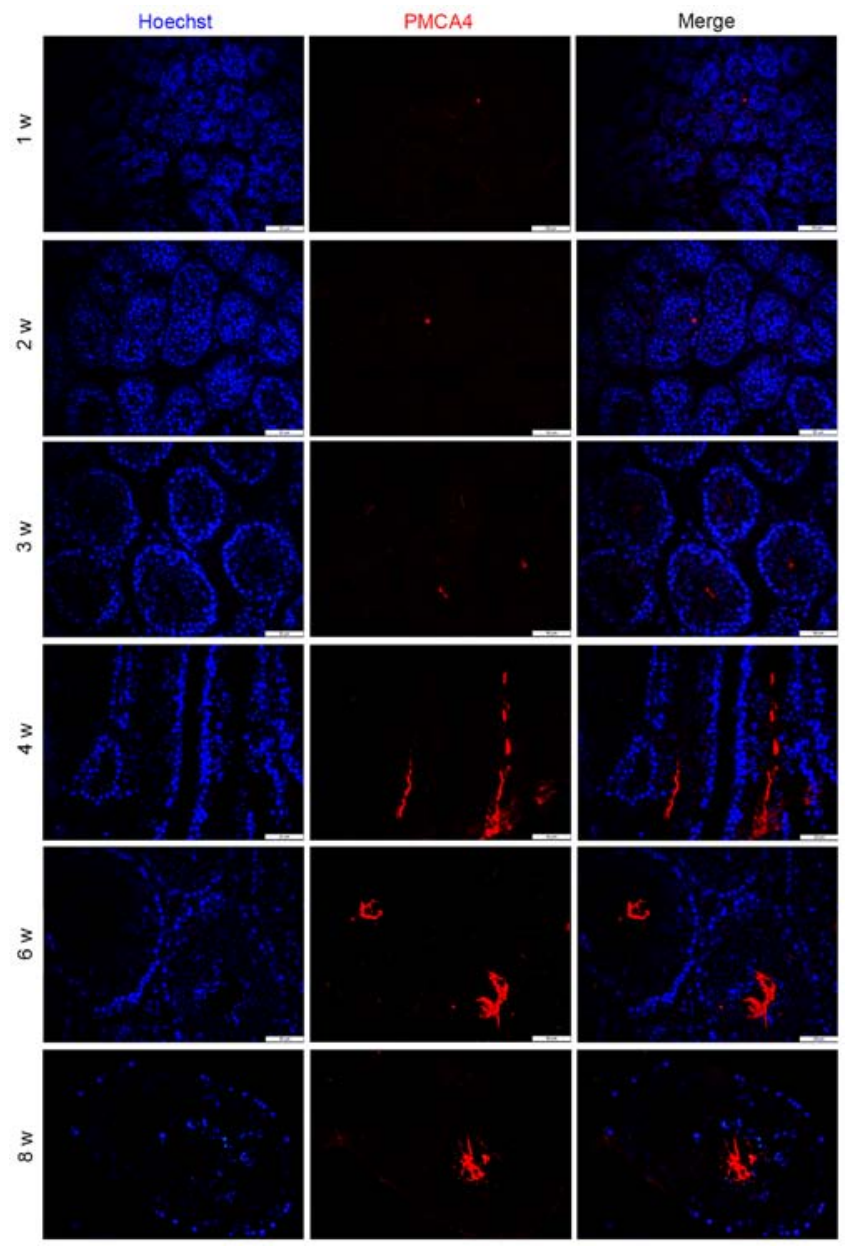

Figure 4. Immunofluorescence staining for PMCA4 in mouse testis at different postnatal weeks. Representative microscopy images show PMCA4 staining (red) and nuclear staining (Hoechst 33342; blue) ( $\mathrm{n}=4)$. Scale bar $50 \mu \mathrm{m}$. PMCA4, ATPase $\mathrm{Ca}^{++}$transporting plasma membrane 4; w, week.

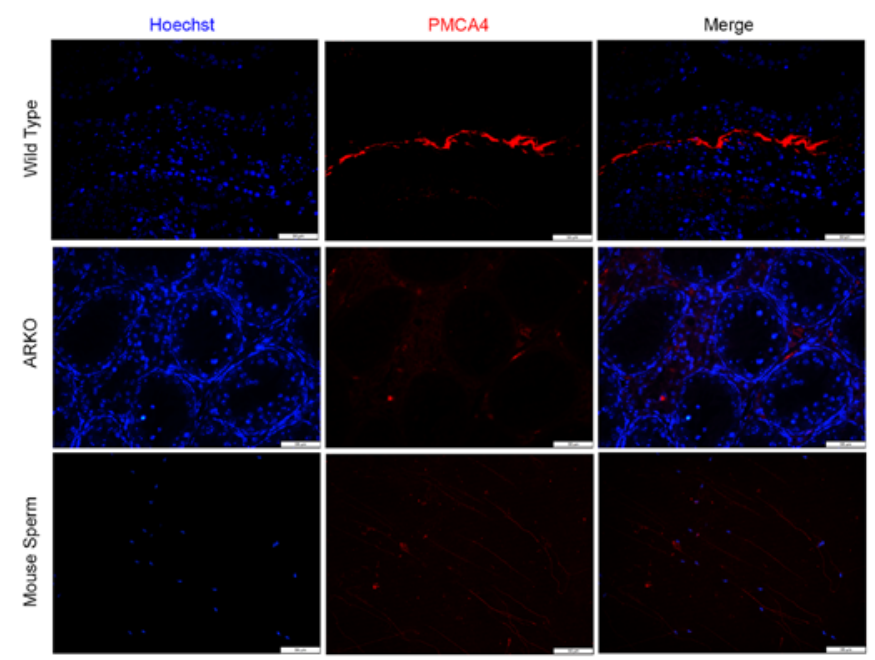

Figure 5. Immunofluorescence staining for PMCA4 in mouse testis from wild type and ARKO mice, and in wild type mouse sperm. Representative microscopy images show PMCA4 staining (red) and nuclear staining (Hoechst 33342 ; blue) $(\mathrm{n}=4)$. Scale bar, $50 \mu \mathrm{m}$. PMCA4, ATPase $\mathrm{Ca}^{++}$transporting plasma membrane 4; ARKO, AR knockout.

the western blotting data in Fig. 3B, minimal florescence signal was observed in the testis from ARKO mice (Fig. 5).

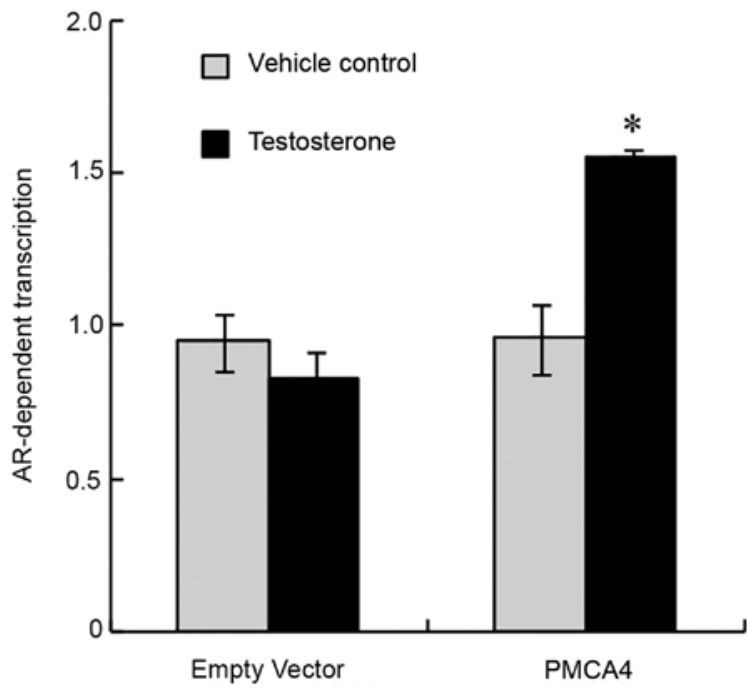

Figure 6. PMCA4 promoter activity is increased by testosterone treatment in TM4 cells in vitro. Dual-luciferase assays were used to detect the effects of testosterone on the PMCA4 promoter activity in TM4 cells. Cells were transfected with empty vector as a control. Results are plotted as fold-change of testosterone-treated relative to vehicle-treated. Data are presented as the mean \pm standard error of the mean $(n=3)$. ${ }^{*} P<0.05$ vs. PMCA 4 vehicle control. PMCA4, ATPase $\mathrm{Ca}^{++}$transporting plasma membrane 4; AR, androgen receptor.

Immunostaining of PMCA4 in healthy mouse sperm revealed that the protein was located at the sperm tail. The present data suggested that PMCA4 may be involved in the movement and motility of the sperm.

PMCA4 promoter is activated by testosterone in vitro. To evaluate whether testosterone and AR affect the transcription of PMCA4, a dual-luciferase assay was used to determine the PMCA4 promoter-driven luciferase activity. As shown in Fig. 6, following treatment of TM4 cells with testosterone or ethanol (vehicle control), cells transfected with the control empty vector exhibited no difference in luciferase activity following exposure to testosterone. By contrast, cells transfected with the PMCA4 promoter-driven vector exhibited significantly increased luciferase activity following testosterone treatment (Fig. 6). The present data indicated that testosterone and AR regulated the promoter activity of PMCA4.

PMCA4 protein expression is regulated by AR in vitro. To further confirm that AR regulates PMCA4 protein expression, TM4 cells were transfected with pcDNA3.1-AR or pcDNA3.1 (empty vector). A significant increase in PMCA4 and AR protein expression levels was observed by western blotting in the AR-overexpressing cells compared with the control-transfected cells (Fig. 7A). In Fig. 7B, cells were pre-incubated for $6 \mathrm{~h}$ with $30 \mu \mathrm{M}$ flutamide, an AR antagonist (14), and then were exposed to $10 \mathrm{nM}$ testosterone for $24 \mathrm{~h}$. As expected, testosterone induced an increase in PMCA4 and AR protein expression levels in the negative control group, which were treated with vehicle for flutamide (Fig. 7B). Flutamide pre-treatment, however, significantly decreased the testosterone-mediated induction in PMCA4 and AR protein expression levels (Fig. 7B). 
A

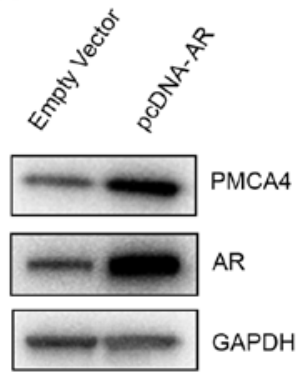

B

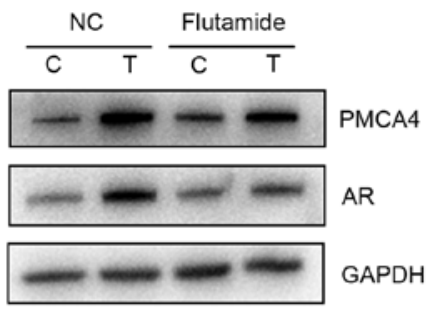

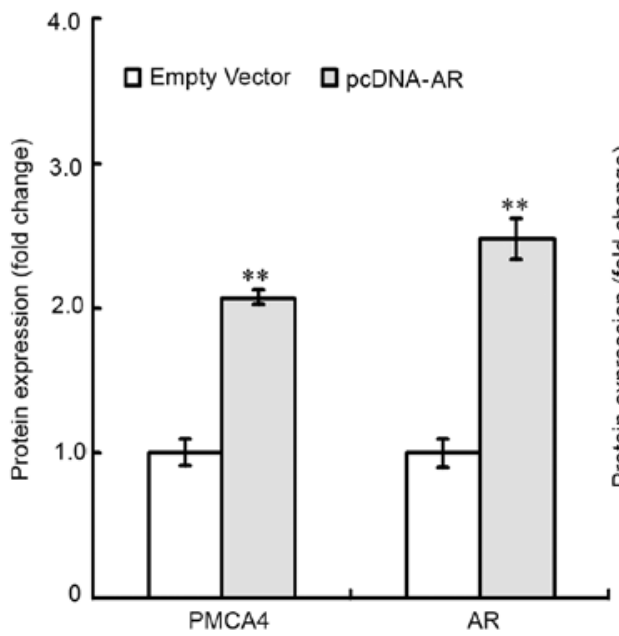

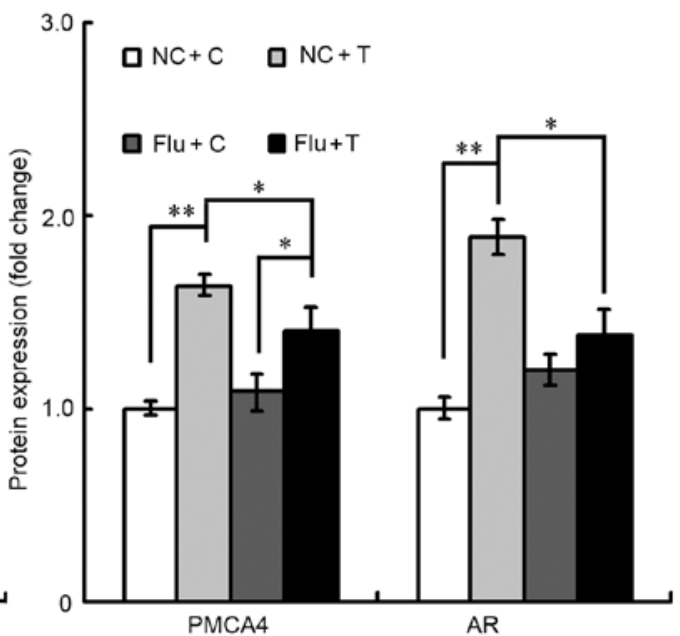

Figure 7. PMCA4 expression is upregulated by androgens and AR in TM4 cells. (A) TM4 cells were transfected with either empty vector or pcDNA-AR, and subsequently the AR and PMCA4 protein expression levels were evaluated via western blotting. GAPDH was used as an internal control. Data are presented as the mean \pm standard error of the mean $(\mathrm{n}=3)$. ${ }^{* * *} \mathrm{P}<0.01$ vs. empty vector group. (B) Cells were pre-treated with flutamide for $6 \mathrm{~h}$, prior to $10 \mathrm{nM}$ testosterone administration for $24 \mathrm{~h}$. AR and PMCA4 protein expression levels were then evaluated by western blotting. Testosterone increased PMCA4 and AR protein expression, and this increase was blocked by the AR antagonist flutamide. Data are presented as the mean \pm standard error of the mean ( $n=3$ ). The statistical significance of the differences between groups was determined by one-way ANOVA followed by all pairwise Holm-Sidak test. " $\mathrm{P}<0.05$ and ${ }^{* *} \mathrm{P}<0.01$, with comparisons shown in brackets. PMCA4, ATPase $\mathrm{Ca}^{++}$transporting plasma membrane 4; AR, androgen receptor; NC, negative control for Flu; C, control for $\mathrm{T}$ and ethanol; $\mathrm{T}$, testosterone; Flu, flutamide.

\section{Discussion}

Ionic homeostasis has a key role in sperm maturation, capacitation and gamete communication (15); the balance of ion transport systems is central to sperm motility (16). Thus, there is little doubt as to the importance of calcium homeostasis in sperm motility and fertilization $(17,18)$.

AR is capable of transmitting testosterone signals by at least two known mechanisms, the classical and non-classical pathways. In the non-classical $\mathrm{Ca}^{2+}$ influx pathway, androgen interacts with a Gq coupled G-protein coupled receptor (GPCR) in the plasma membrane. Phospholipase C (PLC) is then activated to cleave phosphatidylinositol 4,5-bisphosphate (PIP2) into inositol 1,4,5-trisphosphate (IP3) and diacylglycerol (DAG) (19). Decreased PIP2 concentration inhibits ATP-sensitive potassium channels causing membrane depolarization and $\mathrm{Ca}^{2+}$ entry via L-type $\mathrm{Ca}^{2+}$ channels (20). Voltage dependent L-type $\mathrm{Ca}^{2+}$ channels open allowing the influx of $\mathrm{Ca}^{2+}$, which can regulate multiple cellular processes (20). However, the physiological functions regulated by the testosterone-mediated influx of $\mathrm{Ca}^{2+}$ have not been identified (19).

PMCA represents a family of enzymes that extrude $\mathrm{Ca}^{2+}$ from the cytoplasm across the plasma membrane of eukary- otic cells. PMCA4 is the most common PMCA isoform in sperm (21), and has two major splice variants $4 \mathrm{a}$ and $4 \mathrm{~b}$. The latter one is thought to be a key regulator in calcium clearance in murine sperm $(22,23)$, where PMCA4 variant $4 \mathrm{~b}$ deletion disrupts calcium homeostasis and results in the loss of both progressive and hyperactivated sperm motility, ultimately leading to male infertility $(9,24)$. A study conducted by Chen et al (25) reported that PMCA4 was downregulated in seminoma, the most common testicular malignant germ cell tumor, suggesting that PMCA4 has an important role in the spermatogenesis and male fertility; however, the molecular mechanism remains unclear. Therefore, the present study aimed to explore the expression pattern and function of PMCA4 during mouse spermatogenesis.

Results from western blot analysis in different murine tissues revealed that PMCA4 was expressed in the testes, lungs, heart and brain. PMCA4 mRNA and protein expression levels were markedly increased in mice testis at 3 weeks postnatal, which is the time point when the first wave of spermatogenesis occurs (26), suggesting that PMCA4 expression may be primarily restricted to post-meiotic germ cells. This was further confirmed by immunofluorescence results showing that PMCA4 was located at the lumen and inner layers of seminiferous tubules. Previous reports using 
rats (22), as well as bovines (27), have demonstrated that PMCA4 is expressed in the epididymis epithelium. The present findings are in agreement with a previous study published by Patel et al (10), which reported that PMCA4 protein is expressed in the testis and throughout the epididymis. However, the molecular mechanism by which PMCA4 influences spermatogenesis has not been reported to date. In the present study, PMCA4 mRNA levels in testis tissues from SCARKO and ARKO mice were significantly decreased compared with WT controls, and PMCA4 protein expression levels were decreased in ARKO mice compared with WT controls. These findings suggested that AR may regulate PMCA4 expression in mouse testes. By using a luciferase activity assay in vitro, the present study confirmed that activation of AR by testosterone administration increased the activity of the PMCA4 promoter. Cells overexpressing AR in vitro also had higher expression levels of the PMCA4 protein, and the increase in the PMCA4 protein expression induced by testosterone was prevented by pre-treatment with the AR antagonist flutamide.

It was previously reported that PMCA4 and the nitric oxide synthases (NOSs) are interacting partners that have been identified in a quaternary complex including Caveolin-1 (11). A previous study also found that in mouse Sertoli cells AR localizes in the plasma membrane by association to Caveolin-1 (28). The aforementioned evidence supports the hypothesis that AR regulates PMCA4 expression. In general, androgens and AR affect the development of spermatogenic cells in Sertoli cells $(5,29)$. The present results demonstrated that PMCA4 was almost exclusively localized in the sperm tail. A study by Lestari et al (30) reported that PMCA4 expression in the normozoospermia group was much higher than in the asthenozoospermia group due to impaired sperm structure and function, suggesting that PMCA4 defects may be a factor in sperm dysfunction and infertility.

In conclusion, the present study demonstrated that AR regulates PMCA4 expression and that the expression levels of PMCA4 mRNA and protein are downregulated in testes form AR knockout mice compared with WT mice. The present data indicated that PMCA4 may serve a potentially important role in spermatogenesis, and likely in male reproduction. Further studies are needed to better understand the molecular mechanisms by which AR regulates the PMCA4 expression and function in spermatogenesis.

\section{Acknowledgements}

Not applicable.

\section{Funding}

The present study was supported by grants from the Natural Science Foundation (grant no. 31800984), the Science and Technology Planning Project of Guangdong province (grant nos. 2018A0303130337 and A2019565), the Science and Technology Planning Project of Shenzhen municipality (grant nos. JCYJ20180228164047023 and JCYJ20190808095407464) and the Longhua Science and Technology Planning Project (grant nos. 2017029, 1150A20190513BA7B6B0 and 2020006).

\section{Availability of data and materials}

All data generated or analyzed during this study are included in this published article.

\section{Authors' contributions}

RS, QD, HG and ZW performed the experiments. HL and QD analyzed the data and wrote the manuscript. QD obtained funding and revised the manuscript. All the authors read and approved the final version of the manuscript.

\section{Ethics approval and consent to participate}

All experimental protocols involving animals were reviewed and approved by the Ethics Committee of The People's Hospital of Longhua (Shenzhen, China; approval no. LHRY-1907014).

\section{Patient consent for publication}

Not applicable.

\section{Competing interests}

The authors declare that they have no competing interests.

\section{References}

1. Walker WH: Testosterone signaling and the regulation of spermatogenesis. Spermatogenesis 1: 116-120, 2011.

2. Yong EL, Lim LS, Wang Q, Mifsud A, Lim J, Ong YC and Sim KS: Androgen receptor polymorphisms and mutations in male infertility. J Endocrinol Invest 23: 573-577, 2000.

3. Tahmasbpour E, Balasubramanian D and Agarwal A: A multi-faceted approach to understanding male infertility: Gene mutations, molecular defects and assisted reproductive techniques (ART). J Assist Reprod Genet 31: 1115-1137, 2014.

4. O'Hara L and Smith LB: Androgen receptor roles in spermatogenesis and infertility. Best Pract Res Clin Endocrinol Metab 29: 595-605, 2015.

5. De Gendt K, Swinnen JV, Saunders PT, Schoonjans L, Dewerchin M, Devos A, Tan K, Atanassova N, Claessens F, Lécureuil C, et al: A Sertoli cell-selective knockout of the androgen receptor causes spermatogenic arrest in meiosis. Proc Natl Acad Sci USA 101: 1327-1332, 2004.

6. MacLean JA II and Wilkinson MF: The Rhox genes. Reproduction 140: 195-213, 2010.

7. Zhang QX, Zhang XY, Zhang ZM, Lu W, Liu L, Li G, Cai ZM, Gui YT and Chang C: Identification of testosterone-/androgen receptor-regulated genes in mouse Sertoli cells. Asian J Androl 14: 294-300, 2012.

8. Calì T, Brini M and Carafoli E: Regulation of cell calcium and role of plasma membrane calcium ATPases. Int Rev Cell Mol Biol 332: 259-296, 2017.

9. Schuh K, Cartwright EJ, Jankevics E, Bundschu K, Liebermann J, Williams JC, Armesilla AL, Emerson M, Oceandy D, Knobeloch KP, et al: Plasma membrane $\mathrm{Ca}^{2+}$ ATPase 4 is required for sperm motility and male fertility. J Biol Chem 279: 28220-28226, 2004.

10. Patel R, Al-Dossary AA, Stabley DL, Barone C, Galileo DS, Strehler EE and Martin-DeLeon PA: Plasma membrane $\mathrm{Ca}^{2+}$-ATPase 4 in murine epididymis: Secretion of splice variants in the luminal fluid and a role in sperm maturation. Biol Reprod 89: 6, 2013.

11. Olli KE, Li K, Galileo DS and Martin-DeLeon PA: Plasma membrane calcium ATPase 4 (PMCA4) co-ordinates calcium and nitric oxide signaling in regulating murine sperm functional activity. J Cell Physiol 233: 11-22, 2018.

12. Livak KJ and Schmittgen TD: Analysis of relative gene expression data using real-time quantitative PCR and the 2(-Delta Delta $\mathrm{C}(\mathrm{T})$ ) method. Methods 25: 402-408, 2001. 
13. Ma Q, Li Y, Luo M, Guo H, Lin S, Chen J, Du Y, Jiang Z and Gui Y: The expression characteristics of FAM71D and its association with sperm motility. Hum Reprod 32: 2178-2187, 2017.

14. Deng Q, Zhang Z, Wu Y, Yu WY, Zhang J, Jiang ZM, Zhang Y, Liang $\mathrm{H}$ and Gui YT: Non-genomic action of androgens is mediated by rapid phosphorylation and regulation of androgen receptor trafficking. Cell Physiol Biochem 43: 223-236, 2017.

15. Vignini A, Buldreghini E, Nanetti L, Amoroso S, Boscaro M, Ricciardo-Lamonica G, Mazzanti L and Balercia G: Free thiols in human spermatozoa: Are $\mathrm{Na}^{+} / \mathrm{K}^{+}$-ATPase, $\mathrm{Ca}^{2+}$-ATPase activities involved in sperm motility through peroxynitrite formation? Reprod Biomed Online 18: 132-140, 2009.

16. Jimenez T, Sánchez G and Blanco G: Activity of the $\mathrm{Na}, \mathrm{K}-\mathrm{ATPase} \alpha 4$ isoform is regulated during sperm capacitation to support sperm motility. J Androl 33: 1047-1057, 2012.

17. Wood CD, Darszon A and Whitaker M: Speract induces calcium oscillations in the sperm tail. J Cell Biol 161: 89-101, 2003.

18. Fukami K, Yoshida M, Inoue T, Kurokawa M, Fissore RA, Yoshida N, Mikoshiba K and Takenawa T: Phospholipase Cdelta4 is required for $\mathrm{Ca}^{2+}$ mobilization essential for acrosome reaction in sperm. J Cell Biol 161: 79-88, 2003.

19. Rahman F and Christian HC: Non-classical actions of testosterone: An update. Trends Endocrinol Metab 18: 371-378, 2007.

20. Smith LB and Walker WH: The regulation of spermatogenesis by androgens. Semin Cell Dev Biol 30: 2-13, 2014.

21. Calamera J, Buffone M, Ollero M, Alvarez J and Doncel GF: Superoxide dismutase content and fatty acid composition in subsets of human spermatozoa from normozoospermic, asthenozoospermic, and polyzoospermic semen samples. Mol Reprod Dev 66: 422-430, 2003

22. Wilhelm B, Brandenburger T, Post $\mathrm{H}$ and Aumüller G: Expression and localization of PMCA4 in rat testis and epididymis. Histochem Cell Biol 129: 331-343, 2008.

23. Di Leva F, Domi T, Fedrizzi L, Lim D and Carafoli E: The plasma membrane $\mathrm{Ca} 2+$ ATPase of animal cells: Structure, function and regulation. Arch Biochem Biophys 476: 65-74, 2008.
24. Okunade GW, Miller ML, Pyne GJ, Sutliff RL, O'Connor KT, Neumann JC, Andringa A, Miller DA, Prasad V, Doetschman T, et al: Targeted ablation of plasma membrane Ca2+-ATPase (PMCA) 1 and 4 indicates a major housekeeping function for PMCA1 and a critical role in hyperactivated sperm motility and male fertility for PMCA4. J Biol Chem 279: 33742-33750, 2004.

25. Chen Y, Qi C, Xia L and Li G: Identification of novel genetic etiology and key molecular pathways for seminoma via network-based studies. Int J Oncol 51: 1280-1290, 2017.

26. Margolin G, Khil PP, Kim J, Bellani MA and Camerini-Otero RD: Integrated transcriptome analysis of mouse spermatogenesis. BMC Genomics 15: 39, 2014.

27. Brandenburger T, Strehler EE, Filoteo AG, Caride AJ, Aumüller G, Post H, Schwarz A and Wilhelm B: Switch of PMCA4 splice variants in bovine epididymis results in altered isoform expression during functional sperm maturation. J Biol Chem 286: 7938-7946, 2011.

28. Deng Q, Wu Y, Zhang Z, Wang Y, Li M, Liang H and Gui Y: Androgen receptor localizes to plasma membrane by binding to caveolin-1 in mouse sertoli cells. Int J Endocrinol 2017: 3985916 , 2017.

29. Wang RS, Yeh S, Tzeng CR and Chang C: Androgen receptor roles in spermatogenesis and fertility: Lessons from testicular cell-specific androgen receptor knockout mice. Endocr Rev 30: 119-132, 2009

30. Lestari SW, Miati DN, Seoharso P, Sugiyanto R and Pujianto DA: Sperm $\mathrm{Na}^{+}, \mathrm{K}^{+}$-ATPase $\alpha 4$ and plasma membrane $\mathrm{Ca}^{2+}$-ATPase (PMCA) 4 regulation in asthenozoospermia. Syst Biol Reprod Med 63: 294-302, 2017.

(i) (2) This work is licensed under a Creative Common Attribution-NonCommercial-NoDerivatives 4.0 International (CC BY-NC-ND 4.0) License. 